\title{
A Development of Learning Management System for the Practice of E-Learning in Higher Education
}

\author{
Wataru Tsukahara, Fumihiko Anma, Ken Nakayama, Toshio Okamoto \\ Graduate School of Engineering (Educational Organization), TokyoUniversity of Agriculture \\ and Technology, Japan Graduate School of Information Systems, The University of Electro- \\ Communication, Japan
}

Abstract: $\quad$ From 2004 to 2007 our university has a three-year project called 'GP Project' which is part of a national project named "Selected Efforts of the Distinctive University Education Support Program" (Good Practice Project, abbreviated as GP Project), with the support of the ministry of Education, Culture, Sports, Science and Technology of the Japanese Government. In this project we are challenged to replace more than 30 existing courses with e-Learning. The courses must be seamlessly integrated to a course grade information system which has been already in use for years in the educational affairs section. For this integration we introduced a new Learning Management System which is easy to customize so that it can integrates course grade information and eLearning information. We developed a Learning Management System (LMS) by modifying a commercial LMS WebClass with which is easy to add new functions. The first phase system has been started to work and now we are preparing to integrate the course grade information into the LMS. This paper describes our currently running three year university-wide project and then explains the functions of the newly developed Learning Management System.

Keywords: e-Learning, Learning Management System, GP Project, learner's feedback.

\section{INTRODUCTION}

From 2004 to 2007 our university has a three-year national support project named "Selected Efforts of the Distinctive University Education Support Program" (Good Practice Project, abbreviated as GP Project) (MEXT(2004), UEC(2004)). The theme of the project is "The Practice of eLearning with mutual interaction for specialized courses." The project involves the whole Faculty and the UEC office. The Center for Developing e-Learning (CDEL) takes initiative in this project. In this project, we focus on:

Please use the following format when citing this chapter:

Tsukahara, W., Anma, F., Nakayama, K. and Okamoto, T., 2007, in IFIP International Federation for Information Processing, Volume 230, Knowledge Management for Educational Innovation, eds. Tatnall, A., Okamoto, T., Visscher, A., (Boston: Springer), pp. 145-152. 
Use of Digital Portfolio: This is directly related to our theme. We plan to integrate course grade information currently stored in the Educational affairs section database with learner information (such as student ID etc.) stored in the LMS. It enables teachers to give students appropriate suggestions. We currently plan to include:

- subject of essays and submitted essays

- status of submission and submission dates

- status of credits

- grades

- past history of mentoring with summaries

We will start this function from the second term after the current system is integrated with the grade database.

Mentoring and Coaching: Preparing a digital portfolio is not sufficient. It is necessary to provide the function of mentoring/coaching. Because this function is new to teachers of the UEC, we decided to have tutorial for teachers. Mentoring/coaching will be about:

- questions about contents

- recommendations of courses for the learner

- know how of proceeding with learning

- providing curriculum suitable for the learner

These comments are made in reference to the learner's digital portfolio. By appropriately supporting learners in mentoring/coaching, we believe that even the specialized courses can be learned by e-Learning.

Currently, we have 13 contents ready for e-Learning. Topics include business administration, computer literacy, cryptography, image processing, bio-informatics, media literacy, micro-systems, fluid dynamics, software design, fuzzy systems, artificial intelligence, and communication technology. There are various styles of contents:

- video recording or studio recording of the actual lecture

- text and image content written in HTML

- simulation based contents (Active X, Java applet)

Some teachers plan to carry out full e-Learning, and others plan to use it in blended learning style.

In this project we are challenged to replace more than 30 existing courses with e-Learning. In order to realize the above features, a tight connection is important between the LMS in CDEL and the course grade information database in the educational affairs section. The courses must be seamlessly integrated to the course grade information system which has already been in use for years in the educational affairs section. For this integration purpose we needed to introduce a new Learning Management System which is easy to customize so that it can integrates course grade information and eLearning information. We developed a Learning Management System (LMS) based on a commercial LMS WebClass for which is easy to add new functions. We named this LMS WebClass-RAPSODY. 
In the following section we briefly describe the systems we have previously developed to realize our aim in e-Learning and then introduce the new LMS and its function.

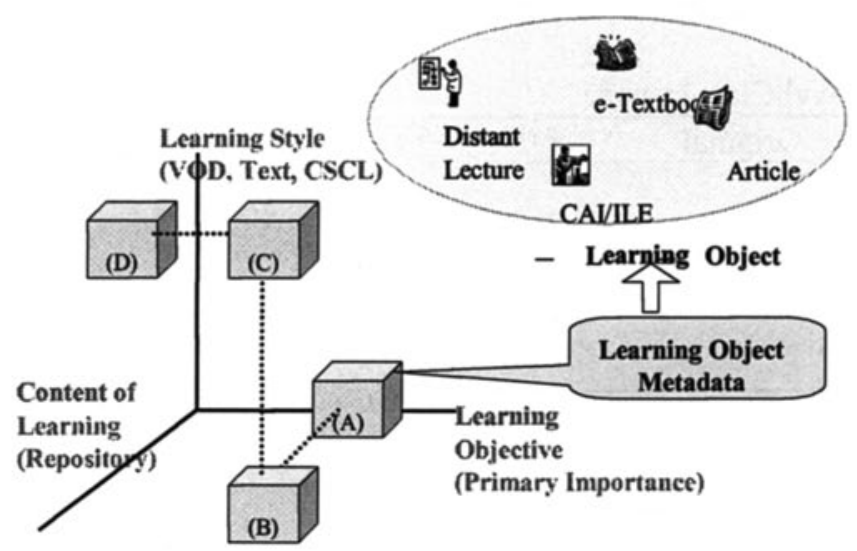

Figure1. Learning Ecological Model

\section{BASIC IDEA: RAPSODY LMS SYSTEMS}

An efficient e-Learning system provides a learning environment which has a high degree of freedom (ALIC (2003), Collins (1999)), letting learners choose appropriate learning contents. The Learning Ecological Model focuses on learning content, objective, and style (Seki et al. (2000, 2002), Okamoto et al. (2001)). RAPSODY is based on this model. On the other hand, teachers want to check access status for improving their course. To realize this, LMSs must handle information such as user identity, curriculum, learning contents, learning history, communication among learners, questions, and answers (Seki et al. (2002), Okamoto et al. (2001), Ymakita et al. (1999), IMS/GLC (2005)). RAPSODY systems (Seki et al. (2000, 2002), Okamoto et al. (2001)) implemented these features. In RAPSODY, learners and teachers can utilize functions such as computer supported cooperative learning (CSCL), authoring, planning curriculum, evaluation, and reporting. Contents are stored with Learning Object Metadata (LOM) proposed by IEEE-LTSC (2005) for the reuse of content. ADL SCORM (ADL (2004)) will be implemented in the next phase. Learner evaluation is done based on learning history. 
There are external modules for sequencing (Seki et al. (2000)), CSCL (Kotani et al. (2004)), and plagiarism (Seki (2004)).

\section{WEBCLASS-RAPSODY}

Although RAPSODY has very advanced features, it is lacking in robustness. So we developed new LMS WebClass-RAPSODY by modifying a commercial LMS WebClass ${ }^{\mathrm{TM}}$ (Table 1).

Table I. Functions added to WebClass system

\begin{tabular}{|c|c|c|c|}
\hline Function & Details & Original & Available \\
\hline \multicolumn{4}{|l|}{ Administration } \\
\hline $\begin{array}{l}\text { Importing Student ID } \\
\text { and course grade }\end{array}$ & $\begin{array}{l}\text { Importing ID and course grade } \\
\text { information from database in } \\
\text { educational affairs section }\end{array}$ & N.A. & 2006 \\
\hline $\begin{array}{l}\text { Learner Management } \\
\text { in UEC structure }\end{array}$ & $\begin{array}{l}\text { Adding, deleting, and analyzing } \\
\text { learners in the unit of year and } \\
\text { faculty. }\end{array}$ & N.A. & 2005 \\
\hline \multicolumn{4}{|l|}{ Authoring } \\
\hline Content Management & $\begin{array}{l}\text { Storing and searching of Learning } \\
\text { Object for ease of reuse. }\end{array}$ & N.A. & 2006 \\
\hline Structure of Contents & $\begin{array}{l}\text { Three layer structure ( Course, } \\
\text { Unit, description ) }\end{array}$ & $\begin{array}{l}\text { Course, Scenario, } \\
\text { Description }\end{array}$ & 2005 \\
\hline $\begin{array}{l}\text { Variety of } \\
\text { question style }\end{array}$ & $\mathrm{n}$-to-n mapping style in question & $\begin{array}{l}\text { Multiple choice, } \\
\text { single choice, text } \\
\text { input }\end{array}$ & 2005 \\
\hline SCORM 1.2 & $\begin{array}{l}\text { Enabling authors for annotating } \\
\text { sequencing order. }\end{array}$ & N.A. & 2006 \\
\hline \multicolumn{4}{|l|}{ Communication } \\
\hline Mailing List Service & $\begin{array}{l}\text { Sending mails among learners of } \\
\text { the course. }\end{array}$ & N.A. & 2005 \\
\hline Discussion board & Discussion board for each course & N.A. & 2004 \\
\hline Mentoring Support & $\begin{array}{l}\text { Digital Portfolio function both } \\
\text { available for leamer and mentor }\end{array}$ & N.A. & 2005 \\
\hline \multicolumn{4}{|l|}{ Analysis } \\
\hline Statistics & $\begin{array}{l}\text { Histogram for standard deviation, } \\
\text { average, highest, lowest scores in } \\
\text { the assignments. }\end{array}$ & $\begin{array}{l}\text { Average, highest, } \\
\text { lowest scores }\end{array}$ & 2005 \\
\hline
\end{tabular}

\section{Administration}

When registering learners, teachers can choose them from an already registered partition which was imported from educational affairs section database. The partition has the usual tree structure so that the learner can be specified by regular/irregular course student, entrance year, faculty, and department (Figure 2). Importing course grade information is available from 2006 in XML format including student $\mathrm{ID}$, name, entrance year, faculty, department, e-mail address, currently taking courses, past courses with grade, course's teacher $\mathrm{ID}$, and teacher name. Using this information the student will receive various suitable suggestions from his learning history.

\section{Authoring}

A problem frequently pointed by teachers is the low variety of question formats at the end of each unit. We added n-to-n mapping question style. 
Authors have to follow the structure of Course-Unit-Description/Question. Figure. 3 show a support for construction of a Unit from Descriptions (left top) and Questions (left bottom). Teachers choose Description/Question into Unit sequence (right) so that Descriptions appear alternately.

\section{Communication}

Supporting mentoring activity is one of our primary focuses. We call the support framework the Digital Portfolio. This can be an asset for a learner to reflect his progress in a course, and in the weekly schedule. Necessary information for the Digital Portfolio for a learner is: his one week course schedule, progress and ranking in a specified course, history of his progress (progress curve) including attendance, submission of essays, past mentoring comments, and submitted reports. Also, mailing list and discussion board can be used in mentoring/coaching.

\section{Analysis}

Teachers want to analyze their course during e-Learning period. In WebClass RAPSODY teachers can obtain basic statistics such as sum, average, maximum, minimum, standard deviation of access time and score. Using this information, teachers analyze their learners and courses (Figure 5).

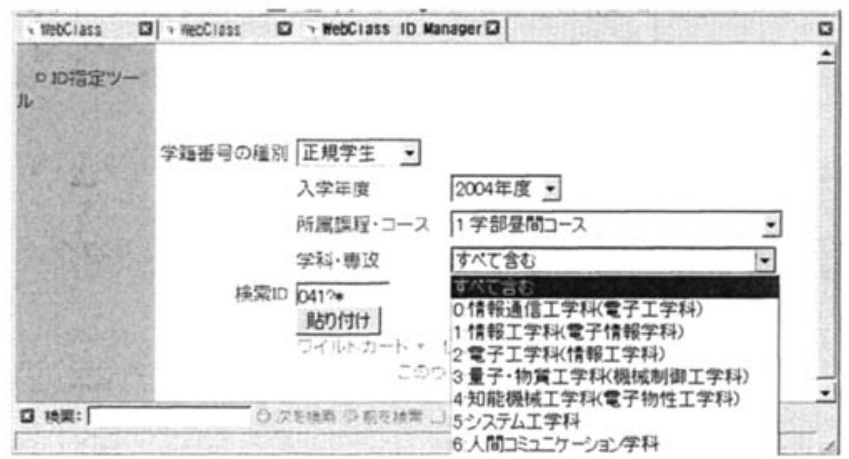

Figure 2. learner's specification

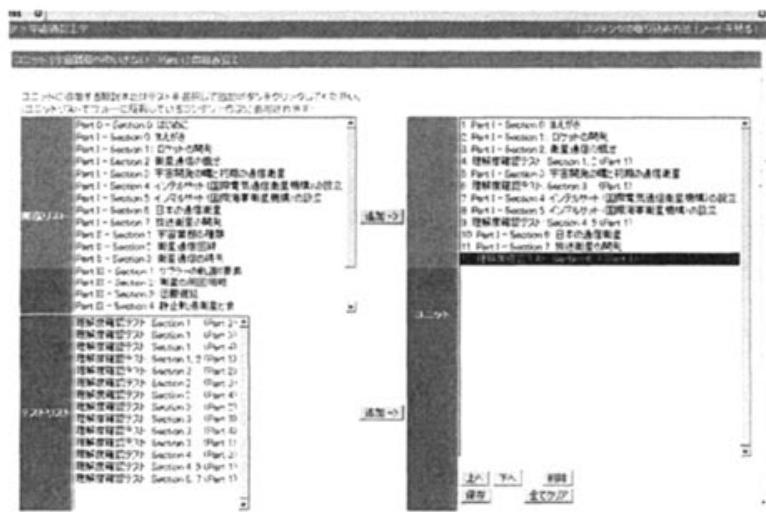

Figure 3. Support for construction 


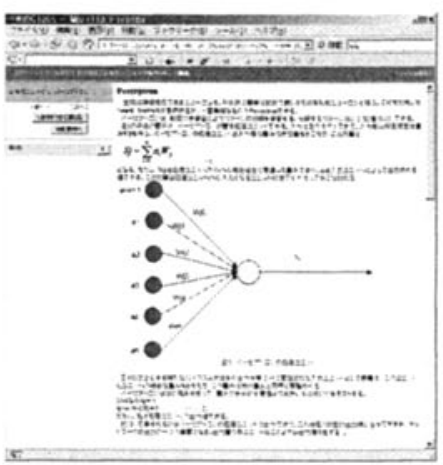

(a) WBT style

Figure 4. Example of stored contents

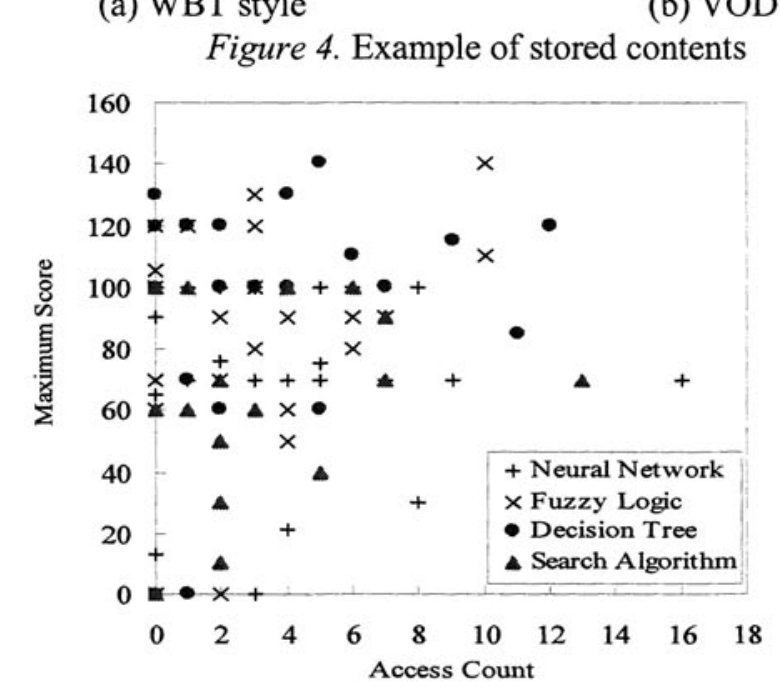

Figure 5. Example of analysis of a course

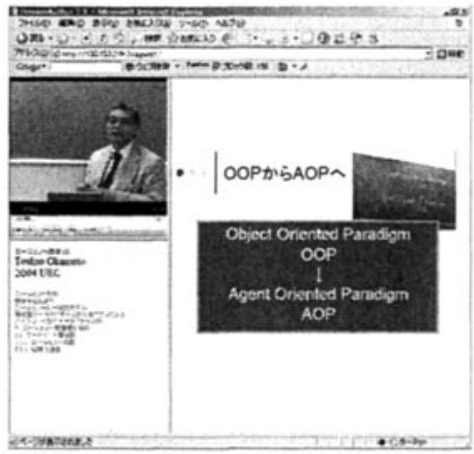

(b) VOD style

\section{ACHIEVEMENT OF THE FIRST YEAR}

As the first year we developed 13 courses from various Faculties (Table 2). There was a variety of course topics and content styles, not only with html, but also with video stream and simulation plug-ins. We plan to add 9 more contents and prepare a total of 22 contents in WebClass-RAPSODY.

Table II. List of the e-Learning contents in UEC GP Project in 2004.

\begin{tabular}{|l|l|l|l|}
\hline Course Name & Semester & Units & Style \\
\hline $\begin{array}{l}\text { Artificial Intelligence and Knowledge } \\
\text { Processing }\end{array}$ & Summer & 15 & Text/Video \\
\hline Knowledge and Media design & Winter & 8 & Text \\
\hline Instrument Technology & Winter & 2 & Text/Video \\
\hline
\end{tabular}




\begin{tabular}{|l|l|l|l|}
\hline $\begin{array}{l}\text { Space Communication Engineering } \\
\text { (Lecture and Practice) }\end{array}$ & Summer & 8 & Text/Video/Simulation \\
\hline $\begin{array}{l}\text { Advanced Information Technology for } \\
\text { Small Businesses with the Open } \\
\text { Source Software }\end{array}$ & Summer & 8 & Text/Video \\
\hline Advanced Image Engineering & Winter & 10 & Text/Video \\
\hline Numerical Fluid Dynamics & Summer & 12 & Text/Simulation \\
\hline Software Systems Design & Summer & 10 & Text/Simulation \\
\hline Media and Systems II & Winter & 8 & Text/Simulation \\
\hline Cryptography & Summer & 12 & Text/Video \\
\hline Media Literacy & Winter & 4 & Text/Video/Simulation \\
\hline Computer Literacy & $\begin{array}{l}\text { Summer and } \\
\text { Winter }\end{array}$ & 13 & Text \\
\hline Exercise in Life Informatics & Winter & 8 & Text/Simulation \\
\hline
\end{tabular}

\section{CONCLUSION}

In this paper we introduced the UEC GP Project and the Center for Developing e-Learning (CDEL), which systematically stores e-Learning contents. For this purpose we developed WebClass-RAPSODY LMS. The system can support registration, authoring, and importing information from the educational affairs section. This enables effective mentoring/coaching by the use of Digital Portfolios.

Currently we have 13 contents from all over the Faculty. These contents contain various topics. In the next year we plan to evaluate how university education would change by this university-wide e-Learning practice.

\section{REFERENCES}

ALIC (2003): e-Learning white paper (in Japanese), Ohmsha, Japan.

Collins, B(1999): Design, Development and Implementation of a WWW-Based CourseSupport System, Proc. $7^{\text {th }}$ International Conference on Computer in Education, Chiba, Japan, pp. 11-18.

MEXT(2004): Distinctive University Educations etc, Support Program (Good Practices): http:/www.mext.go.jp/english/news/2004/05/04052401.htm

IMS/GLC(2005): Global Learning Consortium: http://www.imsproject.org/ .

IEEE LTSC(2005): IEEE P1484.12.3/D8, 2005-02-22 Draft Standard for Learning Technology

- Extensible Markup Language Schema Definition Language Binding for Learning Object Metadata : http://tsc.ieee.org/wg12/files/IEEE_1484_12_03_d8_submitted.pdf

Kotani, T. et al(2004): Development of Discussion Support System based on Values of Favorable Words Influence, Journal of Japanese Society for Artificial Intelligence, Vol. 19, No. 2, pp 95-104.

Okamoto, T. et al(2001): The Distance Ecological Model to Support Self/Collaborative Learning in the Internet Environment, Journal of Educational Technology Research, Vol. 24, pp 21-32.

Seki, K. et al(2000): Construction of the Distance Teacher's Self-Training System based on the School Based Curriculum, Journal of Japanese Society for Information and Systems in Education (in Japanese), Vol. 4, No. 3, pp 307-318. 
Seki, K. et al(2002): an Adaptive Sequencing Method of Learning Object in e-Learning, Proceedings of JET02-1, Japanese Society for Information and Systems in Education (in Japanese), Iwate, Japan, pp 61-66.

Seki, M(2004): Development of Format Free Report Evaluation System in e-Learning Environment, MS Thesis, Graduate School of Information Systems, University of ElectroCommunications, UEC, pp 1-64.

UEC(2004): UEC GP Project, Project Homepage: http://www-gp.ai.is.uec.ac.jp/

Ymakita, T. and Fujii, T(1999): A Hypertext Database for Advanced Sharing of Distributed Web Pages, Proceedings of 15th International Conference on Data Engineering, Chiba, Tokyo, pp 99-100.

WebClass(2005): http://www.webclass.jp

ADL(2004): ADL SCORM 2004 Conformance Requirements Version 1.2: http://www.adlnet.org 